\title{
Citrus sinus peels as a source of polymethoxy flavonoids
}

Mahrous H.Elsayed Mahrous ${ }^{1}$, Ahmed Adel Ashour ${ }^{2}$, Fathy Kandeel El-Fiky ${ }^{1}$ and Saleh Hassan El-Sharkawy ${ }^{2}$

${ }^{1}$ Department of Pharmacognosy, Faculty of Pharmacy, Delta University for Science and Technology, Mansoura, Egypt.

2 Department of Pharmacognosy, Faculty of Pharmacy, Mansoura University, Mansoura, Egypt.

\section{Abstract:}

Food processing waste as Citrus sinus peel is a type of agricultural waste that causes a great environmental problem. The problem could be solved by using this waste for production of valuable chemicals and pharmaceuticals. In this study three flavonoidal compounds were isolated from Citrus sinus peel. The isolated compounds were identified as nobeletin, sinensetin and isosinensetin using ${ }^{13} \mathrm{C}-\mathrm{NMR}$ and ${ }^{1} \mathrm{H}-\mathrm{NMR}$ techniques, in addition to melting point determination.. These compounds have various reported pharmacological activity.

\section{Introduction:}

Natural product contain different compounds that play an important role in drug discovery ${ }^{(1)}$. Agriculture is the backbone of economic system of any country, but increased agricultural production associated with environmental problems as method of treating and disposing wastes adversely affect water, soil and air. Agriculturally related pollution attracts the scope of scientists. Number of reports and symposia developed to solve problem of agriculture waste to retard deterioration of environment quality. Food processing wastes are considered as agriculture production waste. Food processing waste has high volume and low strength and its discharge cause pollution problems as odor problem which is related to growth of microorganisms causing spread of diseases ${ }^{(2)}$.Examples of food processing wastes (fruit wastes) include apple, pear, banana, citrus and citrus include mandarins, lemons, grapefruits and orange residues remaining after processing. About 70.7 million tons of orange produced annually. 30 million tons used in juice industry. Orange peels represent about $50 \%$ of wet fruit mass ${ }^{(3)}$. The previous studies indicate the importance of all parts of fruit especially peels so we decided to examine compound present in orange peels. Citrus sinus is characterized by the presence of a wide range of diverse compounds such as flavonoids, chalcones, psoralens, coumarins, carotenoids, glycosides and essential oils.

\section{Material and methods:}

Plant material: Citrus sinus was collected from Egypt dried in shade for 1 month.

Chemicals: petrolium ether, methylene chloride and methanol (El-Nasr Company for Pharmaceutical Chemicals, Egypt) were of reagent grade, Analytical thin layer chromatography was performed on pre-coated aluminum sheets with silica gel 60 GF254 $(20 \times 20 \mathrm{~cm} \times 0.2 \mathrm{~mm}$ thick). (Merck, Germany).Vanillinsulfuric acid spray reagents used for visualization of TLC. Normal phase chromatography was carried out using silica gel G 60-230 mesh (Merck, Germany) packed by the wet method in the specified solvent. 


\section{Extraction procedure:}

1.5 kilograms of the dried powdered orange peels were extracted by maceration in a percolator with $\mathrm{MeOH}$ (7x2L).

The combined methanolic extracts were concentrated to a syrupy consistency under reduced pressure at $40{ }^{\circ} \mathrm{C}$ and then allowed to dry in a descicator over anhydrous $\mathrm{CaCl} 2$ to a constant weight (150 g, 10 \%). The dried methanolic extract was dissolved in $150 \mathrm{~mL} \mathrm{MeOH}$, diluted with $450 \mathrm{~mL}$ distilled water. The produced solution is fractioned using petroleum ether and methylene chloride.

Methylene chloride fraction(4 g) was dissolved in small volume of methanol $(4 \mathrm{~mL})$ and then mixed well with about $2 \mathrm{~g}$ silica gel for column and left at room temperature to dry and applied onto the top of a silica gel packed glass column $(50 \mathrm{x}$ $4.5 \mathrm{~cm}, 300 \mathrm{~g}$ ), previously packed in methylene chloride. Elution start with methylene chloride and developed by gradient elution using methylene chloride/methanol $100 \%$ (8 L), 99\% (6.5 L), 97\% (3.8 L), $95 \%$ (1.7 L), $90 \%$ (4.5 L), $85 \%(4.7 \mathrm{~L})$, and finally washed with $100 \%$ methanol. Effluents, $100 \mathrm{~mL}$ fraction each, were separately concentrated, monitored by silica gel TLC plates in solvent system $3-15 \% \quad \mathrm{v} / \mathrm{v}$ methylene chloride/methanol and the developed chromatoplates were heated after spraying with vanillin/sulfuric acid spray reagent. Similar fractions were pooled.

Fraction 1 obtained from column chromatography contain compound with $\mathrm{R}_{\mathrm{f}}=$ 0.7 by TLC of silica gel GF254 using Methylene chloride: Methanol (97:3) as the developing solvent. This spot is separated as compound-1 (10 $\mathrm{mg}$ ) by crystallization.

It was pale yellow needles with m. p. $134{ }^{\circ} \mathrm{C}-137{ }^{\circ} \mathrm{C}$.; ${ }^{1} \mathrm{H}-$ NMR ( $\delta$, DMSO-d 6$): \delta H ~ 6.868$ (1H, s, H-3), 7.551 (1H, d, H2'), 7.169 (1H, d, H-5'), 7.657 (1H,dd, H-6'), 3.858 (3H, s, H3'), 4.030 (3H, s, H-4'), 3.885 (3H, s, H-5), 3.858 (3H, s, H6), $3.980(3 \mathrm{H}, \mathrm{s}, \mathrm{H}-7), 3.789$ $(3 \mathrm{H}, \mathrm{s}, \mathrm{H}-8) ;{ }^{13} \mathrm{C}-\mathrm{NMR} \quad(\delta$, DMSO-d 6$): \quad \delta C 160 \quad(\mathrm{C}-2)$, 106.29 (C-3), 175.81(C-4), 147.14 (C-5), 143.5 (C-6), 150.93(C-7), $137.64 \quad$ (C-8), 147.5 (C-9), 114.26(C-10), 119.32(C-1'), 108.91(C-2'), 149 (C-3'), 151.75(C-4'), 111.85(C5'), 123.12(C-6'), 55.71(Methyl-3'), 55.67 (Methyl-4'), 61.14(Methyl-5), 61.39(Methyl-6), 
(Methyl-7), 61.49 (Methyl-8).

Fraction 2 obtained from column chromatography contain compound with $\mathrm{R}_{\mathrm{f}}=$ 0.36 by TLC of silica gel GF254 using Methylene chloride: Methanol (97:3) as the developing solvent. This spot is separated as compound$2(15 \mathrm{mg})$ by crystallization.

It was pale yellow needles with m. p. $175{ }^{\circ} \mathrm{C}-177{ }^{\circ} \mathrm{C}$; ${ }^{1} \mathrm{H}-$ NMR $(\delta$, DMSO-d 6$): \delta \mathrm{H} 6.81$ (1H, s, H-3), 7.23(1H, s, H-8), 7.56(1H, d, H-2'), 7.12(1H, d, H-5'), 7.67(1H,dd, H-6'), $3.9(3 \mathrm{H}, \mathrm{s}, \mathrm{H}-3$ '), 3.86(3H, s, H4') $3.78(3 \mathrm{H}, \mathrm{s}, \mathrm{H}-5), 3.81(3 \mathrm{H}$, s, H-6), 3.97(3H, s, H-7); ${ }^{13} \mathrm{C}-$ NMR $(\delta, \quad$ DMSO-d 6$): \quad \delta \mathrm{C}$ 160.28(C-2), $106.38(\mathrm{C}-3)$, 175.68(C-4), 153.92(C-5), 139.73(C-6), 157.4(C-7), 97.35(C-8), 149(C-9), 112.03(C-10), 123.13(C-1'), 109.15(C-2'), 151.54(C-3'), 151.66(C-4'), 111.64(C-5'), 119.43(C-6'), 55.68(Methyl-3'), 55.86(Methyl-4'),

61.82(Methyl-5),

60.97(Methyl-6),

56.45(Methyl-7).

Fraction 3 fractions (126139) eluted with $99 \%$ methylene chloride/ methanol , showed three spots at $\mathrm{R}_{\mathrm{f}}$ values 0.16 (band 1), 0.2 (band 2) and 0.24(band 3) on silica gel TLC plate developed in methylene chloride - methanol $(97: 3 \mathrm{v} / \mathrm{v})$.
Band 2 and band 3, showed quenching under UV lamp but acquires a yellow color after heating with vanillin/sulfuric acid spray reagent. Group 1 was dissolved in a minimum amount of ethyl acetate $(2 \mathrm{~mL})$, mixed with about $1 \mathrm{~g}$ silica gel, dried and loaded onto the top of a silica gel glass column (35 $\mathrm{x}$ 1 i. d., $20 \mathrm{~g}$ ) previously packed in petroleum ether. Gradient elution (Table 1) is adopted with different proportions of petroleum ether in ethyl acetate $\{50 \% \quad(100 \mathrm{~mL}), 40 \% \quad(100$ $\mathrm{mL}), 30 \%(100 \mathrm{~mL})$ and $20 \%$ $(100 \mathrm{~mL})\}$. The effluents, 25 $\mathrm{mL}$ fractions, were monitored by TLC on silica gel plates, and similar fractions were pooled. Subgroup a, fraction 14, was further purified by rechromatography on silica gel column $(35$ x 1 i. d, 20 g) previously packed in methylene chloride. Elution started with methylene chloride (100 mL), then using methylene chloride / methanol $\{99 \%$ (550 mL), 97\% (390 mL) and 95\% (190 mL) \}. The effluents, $10 \mathrm{~mL}$ fractions, were monitored by TLC on silica gel plates, and similar fractions were pooled. Compound-3 (9 $\mathrm{mg})$ was obtained from fractions $75-85$, and was shown as one spot on TLC silica plate. 


\begin{tabular}{|c|c|c|}
\hline $\begin{array}{l}\text { Table (1): } \\
\text { chromatography } \\
\text { (fraction No. 126 }\end{array}$ & $\begin{array}{l}\text { Results } \\
\text { of } \\
139) .\end{array}$ & $\begin{array}{r}\text { column } \\
\text { roup } 3\end{array}$ \\
\hline \begin{tabular}{|c|} 
Solvent \\
system \\
(petroleum \\
ether /ethyl \\
acetate) \\
\end{tabular} & Fractions & $\begin{array}{l}\text { Fraction } \\
\text { collected }\end{array}$ \\
\hline $50: 50$ & $1-4$ & \\
\hline $60: 40$ & $5-8$ & Subgroup \\
\hline $70: 30$ & $9-12$ & $\mathrm{a}(14)$ \\
\hline $80: 20$ & $12-16$ & \\
\hline
\end{tabular}

Compound-3 was isolated as colorless needles (9 mg), m.p. $197{ }^{\circ} \mathrm{C}-199{ }^{\circ} \mathrm{C}$; 1 H-NMR $(\delta$, DMSO-d6): $\delta \mathrm{H} 6.69(1 \mathrm{H}, \mathrm{s}, \mathrm{H}-$ 3), $6.66(1 \mathrm{H}, \mathrm{s}, \mathrm{H}-6), 7.56(1 \mathrm{H}$, d, H-2'), 7.13(1H, d, H-5'), 7.66(1H,dd, H-6'), 3.94(3H, s, H-3'), 3.92(3H, s, H-4'), 3.96(3H, s, H-5), 4.04(3H, s, H-7), 3.94(3H, s, H-8); 13CNMR $(\delta, \quad$ DMSO-d6): $\delta \mathrm{C}$ 162.9(C-2), 107.09(C-3), 180.29(C-4), $157.82(\mathrm{C}-5)$, 94.32(C-6), 158.98(C-7), 131.84(C-8), 153.98(C-9), 110.40(C-10), 124.94(C-1'), 109.07(C-2'), 150.99(C-3'), 153.13(C-4'), 112.94(C-5'), 121.22(C-6'), 56.6 (Methyl-3'), 56.6(Methyl-4'), 57.06(Methyl5), 56.7(Methyl-7), 61.98(Methyl-8).

\section{Result and discussion:}

The hydro - alcoholic extract of Citrus sinus was farctioned with petroleum ether, methylene chloride and ethylacetate. The methylene chloride fraction was purified and three compounds were obtained. By means of spectroscopic analysis, they were characterized as nobiletin (4), sinensetin $^{(5)}$ and 5,7,8,3',4'pentamethoxyflavone ${ }^{(6)}$.

Compound-1(Figure-1) was isolated as pale yellow needles (10 mg), m. p. $134{ }^{\circ} \mathrm{C}-137{ }^{\circ} \mathrm{C}$, soluble in methylene chloride. It produces florescence under UV lamp $\lambda 254$ and acquires a yellow color after spraying with vanillin/sulfuric acid reagent and heating at $110^{\circ} \mathrm{C}$ for 1 minute. Chromatographic analysis on silica gel TLC plates GF254 and 97\% methylene chloride/methanol showed $R f$ value of 0.7 .

${ }^{13} \mathrm{C}$ spectrum of compound 1 revealed the presence of twenty one signals. The most indicative signals are carbon at $\delta C \quad 175.81$ confirming the presence of a carbonyl group, the olefinic carbons at $\delta \mathrm{C}$ $106.29-160.26$ and the rest of the carbons at the range from 55.67 - 61.88 ppm reflecting their aliphatic nature. From the above data, compound-1 contain methyl-oxy group.

Compound -2 (Figure-2) was isolated as pale yellow needles (15 mg), m. p. $175{ }^{\circ} \mathrm{C}-177^{\circ} \mathrm{C}$, soluble in methylene chloride. 
It produces florescence under UV lamp $\lambda 254$ and acquires a yellow color after spraying with vanillin/sulfuric acid reagent and heating at $110^{\circ} \mathrm{C}$ for 1 minute. Chromatographic analysis on silica gel TLC plates GF254 and 97\% methylene chloride/methanol showed $R_{f}$ value of 0.36

${ }^{13} \mathrm{C}$ spectrum of compound-2 revealed the presence of twenty one signals. The most indicative signals are carbon at $\delta C \quad 175.68$ confirming the presence of a carbonyl group, the olefinic carbons at $\delta \mathrm{C}$ $106.38-160.28$ and the rest of the carbons at the range from 55.68 - 61.82 ppm reflecting their aliphatic nature. From the above data, Compound-2 contain methyl-oxy group.

Compound-3(Figure-3) was isolated as colorless needles ( 9 mg), m. p. $197{ }^{\circ} \mathrm{C}-199{ }^{\circ} \mathrm{C}$, soluble in methylene chloride. It produces florescence under UV lamp $\lambda 254$ and acquires a yellow color after spraying with vanillin/sulfuric acid reagent and heating at $110^{\circ} \mathrm{C}$ for 1 minute. Chromatographic analysis on silica gel TLC plates GF254 and 97\% methylene chloride/methanol showed $R_{\mathrm{f}}$ value of 0.2 .

${ }^{13} \mathrm{C}$ spectrum of compound-3 revealed the presence of twenty one signals. The most indicative signals are carbon at $\delta C \quad 180.29$ confirming the presence of a carbonyl group, the olefinic carbons at $\delta \mathrm{C} 94.32$ - 162.9 and the rest of the carbons at the range from 56.6 $61.98 \mathrm{ppm}$ reflecting their aliphatic nature. From the above data, Compound-3 contain methyl-oxy group.<smiles>COc1cc(OCOc2c(OC)c(OC)c(OC)c(OC)c2C(C)=O)c(OC)c(OC)c1C(C)=O</smiles>

(Figure-1)

(Figure-2)<smiles>COc1cc(OC)c2c(=O)ccoc2c1OC</smiles>

(Figure-3)

\section{References:}

1. Koehn, F.E. and G.T. Carter, The evolving role of natural products in drug discovery. Nature reviews Drug discovery, 2005. 4(3): p. 206220.

2. Loehr, R., Agricultural waste management:roblems, processes, and approaches. 2012: Elsevier.

3. Choi, I.S., et al., A lowenergy, cost-effective approach to fruit and citrus peel waste processing for bioethanol production. Applied Energy, 2015. 140: p. 65-74. 
4. Nagase, H., et al., Nobiletin and its related flavonoids with CRE-dependent transcription-stimulating and neuritegenic activities. Biochemical and biophysical research communications, 2005. 337(4): p. 1330-1336.

5. Hossain, M.A. and S.M. Rahman, Isolation and $c$ haracterisation of flavonoids from the leaves of medicinal plant Orthosiphon stamineus. Arabian Journal of Chemistry, 2015. 8(2): p. 218221.

6. Uckoo, R.M., et al., Polymethoxyflavones isolated from the peel of Miaray Mandarin (Citrus miaray) have biofilm inhibitory activity in Vibrio harveyi. Journal of agricultural and food chemistry, 2015. 63(32): p. 7180-7189. 